\title{
L'ÉBULLITION DOMESTIQUE DU LAIT. SON ACTION SUR LA FLORE MICROBIENNE ET LES CONSTITUANTS DU LAIT (1)
}

\author{
par \\ M. PLOMMET \\ Station centrale de Microbiologie et Recherches laitières \\ Jouy-en-Josas
}

En France, c'est un fait bien connu, la ménagère fait bouillir son lait. A cela deux raisons : la première, d'ordre pratique, est que très souvent le lait pasteurisé du commerce ne se conserve pas dans les conditions de température où on le place habituellement; la seconde, plus théorique, est le doute manifesté par de nombreuses personnes quant à l'efficacité de la pasteurisation en tant que mesure d'hygiène destinée à détruire les microbes pathogènes du lait.

Dans les pays les plus évolués en matière d'hygiène du lait, le lait est soit livré pasteurisé et consommé sous cette forme (U.S.A., pays anglo-saxons et scandinaves), soit livré cru et bouilli à domicile (Suisse). Les conditions géographiques particulières de la Suisse - agglomérations urbaines relativement peu étendues et situées à proximité des lieux de production - ainsi que l'habitude qu'ont les Suisses de ne consommer le lait qu'à l'état de café au lait chaud rendent cette dernière méthode de distribution et d'assainissement logique. En France, il serait à peu près impossible de distribuer le lait cru dans les grandes agglomérations en raison de l'étendue des bassins laitiers qui ne sont d'ailleurs pas toujours situés à proximité des villes à desservir (cas du Midi de la France). On a done recours à la pasteurisation et lorsque le lait est bouilli à domicile il a déjà été pasteurisé une ou deux fois.

Les travaux consacrés à la pasteurisation sont maintenant innombrables et la méthode est parfaitement connue, tant dans ses conditions d'application que dans ses résultats [1], [5], [20]. Par contre l'ébullition domestique du lait, bien qu'officiellement recommandée en France, est en fait mal connue et la bibliographie des travaux la concernant est très réduite. Il faut remonter à GAY-LUSSAC qui donne une consécration scientifique à l'ébullition ménagère en montrant qu'on peut conserver le lait indéfiniment à la condition de le faire bouillir tous les deux jours [2]. PASteur a démontré de son côté "que des vibrions peuvent naître dans un liquide de la nature du lait qui a subi une ébullition de plusieurs minutes à la température de $100^{\circ} \ldots$ (mais) si l'on pratique l'ébulli-

(1) Anin. Inst. Nat. Rech. Agro. Série E (Ann. Tech. Agric., 1956, 5, 493-519). 
tion à $110^{\circ}$ ou $112^{\circ}$ sous une pression d'une atmosphère et demie, jamais le lait ne donnera d'infusoires" [3]. Soxhlet, en 1887, invente un appareil pour la stérilisation du lait en flacons par immersion de ceux-ci dans l'eau bouillante En 1916, J. Renault et P.-P. Lévy [4], désireux d'améliorer le procédé de Soxhlet dans son application à l'alimentation des nourrissons, publient une étude sur l'ébullition du lait et concluent :

"La cuisson de trois quarts d'heure recommandée par SoxhlET n'a aucun avantage sur une cuisson plus courte (moins d'une minute) en ce qui concerne le Bacillus subtilis et autres saprophytes. L'une et l'autre tuent les bactéries et empêchent la coagulation subtilienne pendant les vingt-quatre heures qui suivent le chauffage; ni l'une ni l'autre ne détruisent les spores qui se transforment en bactéries les jours suivants."

Ils ajoutent que pour détruire les pathogènes, il suffit que l'eau du bain-marie atteigne $94^{\circ}$ à $96^{\circ}$, qu'une ébullition prolongée n'a donc pas d'utilité, que les biberons doivent être refroidis et mis au frais et qu'ils doivent être consommés dans les vingt-quatre heures.

Si nous savons bien que l'ébullition domestique est la règle générale dans les foyers français, nous ignorons les conditions habituelles de cette ébullition, spécialement en ce qui concerne le lait lui-même : son origine, le traitement qu'il a pu subir, les modalités de son chauffage, de sa conservation et de son utilisation. Avant d'étudier l'ébullition, il nous a semblé qu'il fallait savoir comment, dans la pratique, la ménagère fait bouillir son lait. En effet, les opinions des hygiénistes et les recommandations qu'ils donnent sur l'ébullition du lait sont assez différentes les unes des autres notamment en ce qui regarde la durée de maintien à l'ébullition et l'on peut se demander comment ces recommandations sont appliquées, en fait, dans la pratique ménagère. La première partie de notre travail a donc été consacrée à une enquête, effectuée au début de l'année 1955 auprès de 128 personnes représentant 128 foyers français différents pour connaître leur manière de traiter et d'utiliser le lait à la maison.

Pendant le chauffage et le refroidissement une "peau" mince et plissée apparaît à la surface du lait et va en s'épaississant. En même temps il se forme sur les parois chaudes de la casserole un "gratin" d'autant plus épais que l'ébullition est plus prolongée et que le lait est plus acide. Les constituants de la peau et du gratin sont ou bien perdus complètement (cas du "gratin") ou bien utilisés incomplètement (cas de la "peau "). Dans une deuxième partie nous avons cherché à estimer la perte qui en résulte en étu- 
diant les quantités de matière sèche totale, de matière grasse et de protéines contenues d'une part dans le lait avant l'ébullition, d'autre part dans le lait, la peau et le gratin immédiatement après l'ébullition et après vingt-quatre heures de repos.

Enfin, puisque l'ébullition est surtout un procédé de destruction des microbes et de conservation du lait, nous avons, dans une troisième partie, étudié les germes résistant à l'ébullition et leur action sur le lait au cours de sa conservation. Notre étude n'a pas porté sur les germes pathogènes non sporulés le plus souvent rencontrés dans le lait (Bacille tuberculeux, Brucelle). On sait qu'une pasteurisation efficace ( $72^{\circ}$ pendant 15 secondes, par exemple) les détruit. Un chauffage à $100^{\circ}$ détruit à fortiori tous ces germes pathogènes. Si certains d'entre eux étaient encore vivants dans le lait soumis à l'ébullition domestique cela ne pourrait être dû qu'à un chauffage incomplet d'une certaine fraction du liquide.

\section{ENQUETE SUR LUTILISATION DOMESTIQUE DU LAIT}

\section{A. Conditions de l'enquête}

Le questionnaire, reproduit dans le tableau I, a été distribué au cours du premier trimestre 1955 à environ 300 personnes. 128 réponses nous sont parvenues des départements suivants : Seine et Seine-et-Oise (Paris et banlieue) 97 réponses; autres départements (Cher, Eure, Haute-Savoie, Isère, Loir-et-Cher, Loiret, Meurthe-et-Moselle, Nord, Seine-et-Marne, Seine-Maritime, Puy-de-Dôme, Yonne) 31 réponses.

\section{TABLEAU I}

\section{QUESTIONNAIRE}

Nom Commune

Indiquez quelles sont vos habitudes. Répondez par OUI ou NON.

$1^{\circ}$ Quel type de lait achetez-vous ?

- pasteurisé, en bouteille.

- pasteurisé, en bidon

- $\mathrm{cru}$

$2^{\circ}$ En achetez-vous tous les jours?

3o Est-il consommé dans les 24 heures ?..............., Sinon, en combien de temps?.

$4^{\circ}$ Le faites-vous bouillir ?. les questions $4,5,6,7$.

Si oui, - combien de temps après l'achat : Si vous répondez non, ne regardez pas heures

- combien de temps le faites-vous bouillir ?

- jusqu'à ce qu'il monte ? minutes? 
$5^{\circ}$ Vous arrive-t-il de le faire bouillir plusieurs fois ?

- pour le conserver plus longtemps?.

- dans un autre but (indiquez-le) ?

$6^{\circ}$ Utilisez-vous ce lait bouilli encore chaud ?

- en totalité

- en partie

- uniquement après refroidissement

Si vous ne l'utilisez pas immédiatement après l'ébullition, le faites-vous refroidir (en mettant la casserole dans l'eau, par exemple) et le conservezvous au frais (cave, réfrigérateur) ? ou bien le laissez-vous dans un coin de la cuisine refroidir seul ?

$7^{\circ}$ Laissez-vous la peau dans ce lait, pour qu'elle soit absorbée en boisson (café au lait, chocolat)?

Ou bien la récoltez-vous à part pour la cuisine ?

Ou la recueillez-vous dans la passoire pour la jeter ou la donner aux animaux?

$8^{\circ}$ Consommez-vous du lait "nature " ? (c'est-à-dire sans café, chocolat)............ chaud. sucré refroidi. non sucré

9. Etes-vous satisfait du lait que vous pouvez vous procurer ? Si non, pourquoi ne l'êtes-vous pas? Mauvais goût

Mauvaise conservation

Pas assez erémeux

\section{B. - Résultats}

Ils sont indiqués dans les tableaux II et III.

TABLEAU II

TYPE DE LAIT AGHETÉ D'APRÈS LES RÉPONSES AU QUESTIONNAIRE RÉPARTITION ENTRE PARIS ET LA PROVINGE

\begin{tabular}{|c|c|c|c|}
\hline Type de Lait & Paris & Province & Total \\
\hline & & & \\
\hline Pasteurisé conditionné $\ldots \ldots \ldots \ldots \ldots$ & 52 & 8 & 60 \\
\hline Pasteurisé ; livré en bidons ........ & 15 & 2 & 17 \\
\hline "Cru» $\ldots \ldots \ldots \ldots \ldots \ldots \ldots \ldots$ & 28 & 21 & 49 \\
\hline "Stérilisé " concentré ou en poudre... & 2 & & 2 \\
\hline Total $\ldots \ldots \ldots \ldots \ldots \ldots \ldots$ & 97 & 31 & 128 \\
\hline
\end{tabular}

\section{C. - Discussion}

On constate (tableau II), que la majorité des consommateurs de Paris utilisent le lait pasteurisé conditionné. Ce n'est pas sans surprise, par contre, que l'on apprend que 28 réponses de personnes interrogées à Paris font mention de l'achat de lait “cru » : la vente de lait cru ne représente que $1 \%$ environ du lát vendu dans le 
département de la Seine. Cette confusion entre le lait cru et le lait pasteurisé livré en bidons prouve l'ignorance de la ménagère en ce qui concerne les qualités et l'origine du produit qu'elle achète.

Cependant le lait est un aliment de tous les jours ; presque toutes les ménagères en achètent quotidiennement et le consomment dans la journée. Un petit nombre, bien qu'achetant du lait tous les jours, ne le consomme pas toujours dans les vingt-quatre heures. On ne constate pas de corrélation entre le type de lait acheté et la fréquence d'achat ou la durée d'utilisation.

Les réponses données à la quatrième question (tableau I) confirment l'opinion que la grande majorité des consommateurs font bouillir leur lait. Toutefois, cette pratique n'est pas une règle absolue surtout parmi les acheteurs de lait conditionné.

TABLEAU III

UTILISATION DOMESTIQUE DU LAIT

Pour cent des réponses faveur de la question posée

Fréquence d'achat et durée d'utilisation :

achat quotidien $\ldots \ldots \ldots \ldots \ldots \ldots \ldots \ldots \ldots \ldots \ldots \ldots \ldots \ldots$

consommation en 24 heures ................ 80

achat quotidien et consommation en 24 heures ....... 75

Conditions de l'ébullition :

ébullition à domicile $\ldots \ldots \ldots \ldots \ldots \ldots \ldots \ldots \ldots$

pas d'ébullition à domicile ................ 14 *

Moment auquel a lieu l'ébullition :

ébullition aussitôt après l'achat .............. 12

avant la troisième heure qui suit l'achat ......... 58

au moment de l'emploi ................. 5

pas de réponse ..................... 25

Durée de l'ébullition :

jusqu'à montée du lait $\ldots \ldots \ldots \ldots \ldots \ldots \ldots \ldots \ldots \ldots \ldots \ldots$

moins de trois minutes $\ldots \ldots \ldots \ldots \ldots \ldots \ldots \ldots \ldots \ldots$

de trois à cinq minutes $\ldots \ldots \ldots \ldots \ldots \ldots \ldots \ldots \ldots \ldots$

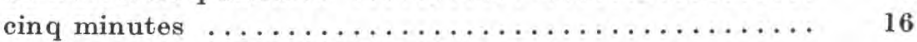

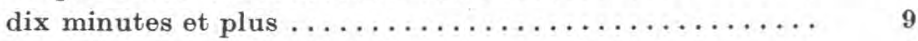

pas de réponse ...................... 4

Répétition des ébullitions :

une seule ébullition $\ldots \ldots \ldots \ldots \ldots \ldots \ldots \ldots \ldots \ldots \ldots \ldots \ldots \ldots$

parfois plusieurs ébullitions ............... 40

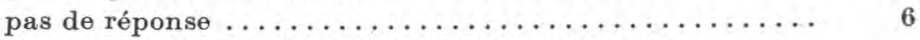

Mode de refroidissement du lait après l'ébullition :

pas de refroidissement autre que le refroidissement spon-

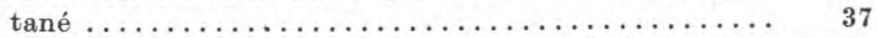

refroidissement provoqué ................ 42

consommation immédiate du lait .............. 13

pas de réponse .................... 8 
Utilisation de la "peau "du lait:

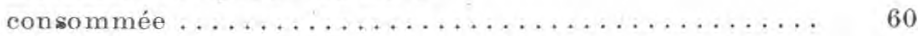

prélevée et jetée ...................... 9

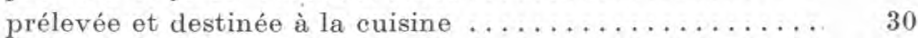

Consommation du lait en nature (sans adjonction d'aucune sorte) :

consomment quelquefois $\ldots \ldots \ldots \ldots \ldots \ldots \ldots \ldots \ldots \ldots \ldots \ldots \ldots \ldots$ 44*

Appréciation d'ensemble portée sur le lait du commerce :

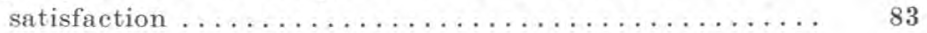

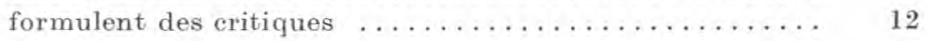

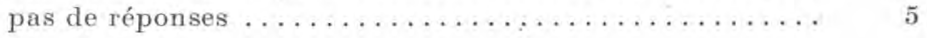

* Parmi les 14\%:

10 achètent du lait conditionné.

3 - du lait en bidons.

l - autre lait.

** Parmi les $44 \% 37$ consomment leur lait après ébullition.

$7 \quad-\quad$ sans ébullition préalable.

L'ébullition est en général faite dans les heures qui suivent l'achat comme si cette opération ne souffrait aucun retard ; cependant quelques personnes négligentes répondent " quand j'y pense, quand j'ai le temps... " D'autres, disposant en général d'un réfrigérateur, attendent le moment de l'emploi pour faire bouillir le lait. Ce procédé, dont nous discuterons plus loin l'intérêt au point de vue bactériologique, n'est donc adopté que par une minorité de consommateurs.

Il n'y a guère de règles précises concernant la durée de l'ébullition qui est, en fait, fantaisiste. Peut-être la formule «jusqu'à ce que le lait se sauve " aurait-elle groupé une large majorité ? On note des ébullitions de 15 minutes, d'ailleurs justifiées par des remarques de ce genre: "pour des raisons d'asepties..." "sur recommandation médicale..."

Les méthodes de refroidissement employées ne sont pas toujours d'une bien grande efficacité, mais nous en avons cependant toujours tenu compte dans les statistiques comme traduisant au moins une intention. Il faut remarquer que le peu de soins apportés au refroidissement après l'ébullition n'est sans doute pas sans rapport avec l'obligation qu'ont de nombreuses ménagères de faire bouillir de nouveau le lait pour le conserver.

La "peau " est prélevée avant la consommation dans $39 \%$ des cas : c'est-à-dire que $39 \%$ des consommateurs absorbent un lait partiellement écrémé. Un petit nombre $(9 \%)$ perdent entièrement la matière grasse de la "peau " qu'ils jettent. Il est intéressant de rapprocher ces chiffres du fait que la valeur marchande de la matière grasse représente environ les trois quarts de celle du lait, et que le 
lait écrémé est une boisson à laquelle on n'accorde en France que peu d'estime.

Le lait en "nature " est un lait qui n'a pas subi d'adjonction autre que celle du sucre. On peut être surpris de la proportion élevée de personnes qui disent consommer du lait sous cette forme, d'autant plus qu'il s'agit 37 fois sur $44 \mathrm{du}$ lait bouilli, c'est-à-dire d'un lait dont la saveur (goût du cuit) n'est pas particulièrement agréable. Ces personnes se répartissent également parmi les acheteurs de lait conditionné et les acheteurs de lait en bidons.

L'apprécition d'ensemble portée par le consommateur sur la qualité du lait qu'il achète est flatteuse mais surprenante, étant donnée la forte proportion de lait consommé après ébullition et la durée de conservation insuffisante que l'on reproche souvent au lait vendu dans le commerce. Il semble que cette appréciation doive être interprétée plutôt comme traduisant un état d'indifférence et une méconnaissance des qualités que possède un bon lait de consommation plutôt qu'une réelle satisfaction.

Il pourrait éventuellement être intéressant d'étendre davantage cette enquête en étudiant la répartition des réponses selon les milieux sociaux.

Les résultats que nous avons obtenus permettent de schématiser ainsi le comportement de la ménagère française : elle achète du lait de plusieurs types, mais n'a pas d'idées bien précises sur ce que représente chacun de ces types. Ils sont caractérisés surtout à ses yeux par la nature du récipient dans lequel le lait est vendu (lait en bouteilles, lait en bidons, etc.).

De toute manière la ménagère fait bouillir son lait (dans $86 \%$ des cas) mais ne sait pas comment le faire bouillir ni comment le conserver, sinon en le faisant bouillir de nouveau.

Quelques-unes seulement $(5 \%)$ le conservent au froid et ne le font bouillir qu'au moment de l'emploi. Parmi les acheteurs de lait pasteurisé vendu en bouteilles, $22 \%$ ne le font pas bouillir.

Très généralement, les consommateurs français sont satisfaits du lait qu'ils se procurent mais ignorent la plupart du temps ce qu'est un bon lait : $7 \%$ seulement le consomment en nature (c'est-à-dire sans café ni chocolat) non bouilli.

\section{COMPOSITION DU LAIT BOUILLI}

\section{A. - Matériel et méthodes d'analyse}

Le lait utilisé est du lait pasteurisé vendu dans le commerce. Un litre de ce lait est versé dans une casserole d'aluminium (diamètre $140 \mathrm{~mm}$., hauteur $140 \mathrm{~mm}$., épaisseur de la tôle $2 \mathrm{~mm}$.) et 
chauffé sur un réchaud à gaz jusqu'au moment de la montée du lait. On le laisse ensuite refroidir spontanément à l'air libre.

La «peau » est prélevée soit après 30 minutes, soit après 24 heures à l'aide d'une écumoire de ménage, en prenant soin de ne pas laisser - de peau adhérente à la casserole et en égouttant rapidement. Elle est pesée puis homogénéisée par agitation vigoureuse dans un flacon contenant des billes de verre.

Le lait bouilli débarrassé de la "peau " et du "gratin ", est pesé puis transvasé.

Le "gratin ) est pesé (par différence avec le poids de la casserole vide) puis râclé avec une spatule et homogénéisé de la même manière que la peau.

La détermination de la substance sèche est faite par dessiccation à l'étuve à $100^{\circ}$ de 10 grammes environ de lait, et de 1 gramme environ de "peau " ou de "gratin ».

La teneur en matière grasse est déterminée par la méthode Rose-Gottlieb, sur des échantillons de 10 grammes environ de lait, et 1 gramme environ de "peau " ou de "gratin ".

La teneur en protéines est déterminée par dosage de l'azote total au Kjeldahl sur des échantillons d'environ 1 gramme de lait et $0 \mathrm{gr}$. 1 à $0 \mathrm{gr} .2$ de "peau " ou de "gratin ».

\section{B. - Résultats}

10 Dans les conditions qui viennent d'être décrites, la perte de poids résultant de l'évaporation au cours de l'ébullition et des trente minutes de refroidissement est d'environ 50 grammes par litre de lait. Après vingt-quatre heures de refroidissement et de conservation, elle est voisine de 80 grammes par litre de lait.

$2^{\circ}$ Trente minutes après l'ébullition le poids de la "peau» est en moyenne de 10 grammes. Après vingt-quatre heures il est de 58 grammes.

$3^{\circ}$ Le poids de "gratin " varie de 16 grammes à $17 \mathrm{gr} .5$.

$4^{\circ}$ Nous avons représenté dans le tableau IV les quantités de matière sèche $(S)$, de matière grasse $(G)$ et de protéines $(P)$ se trou. vant respectivement d'une part dans le lait avant l'ébullition (ramené à 100), d'autre part dans le lait après l'ébullition, dans la "peau" et dans le "gratin". Nous avons calculé les rapports $\frac{G}{S}$ et $\frac{G+P}{S}$ donnant les proportions de matière grasse et de protéines dans la matière sèche des différents produits examinés. 
TABLEAU IV

RÉPARTITION, EN POUR GENT, DES CONSTITUANTS DU LAIT GRU OU PASTEURISÉ ENTRE LES DIFFÉRENTES FRAGTIONS D'UNE CASSEROLE DE LAIT BOUILLI

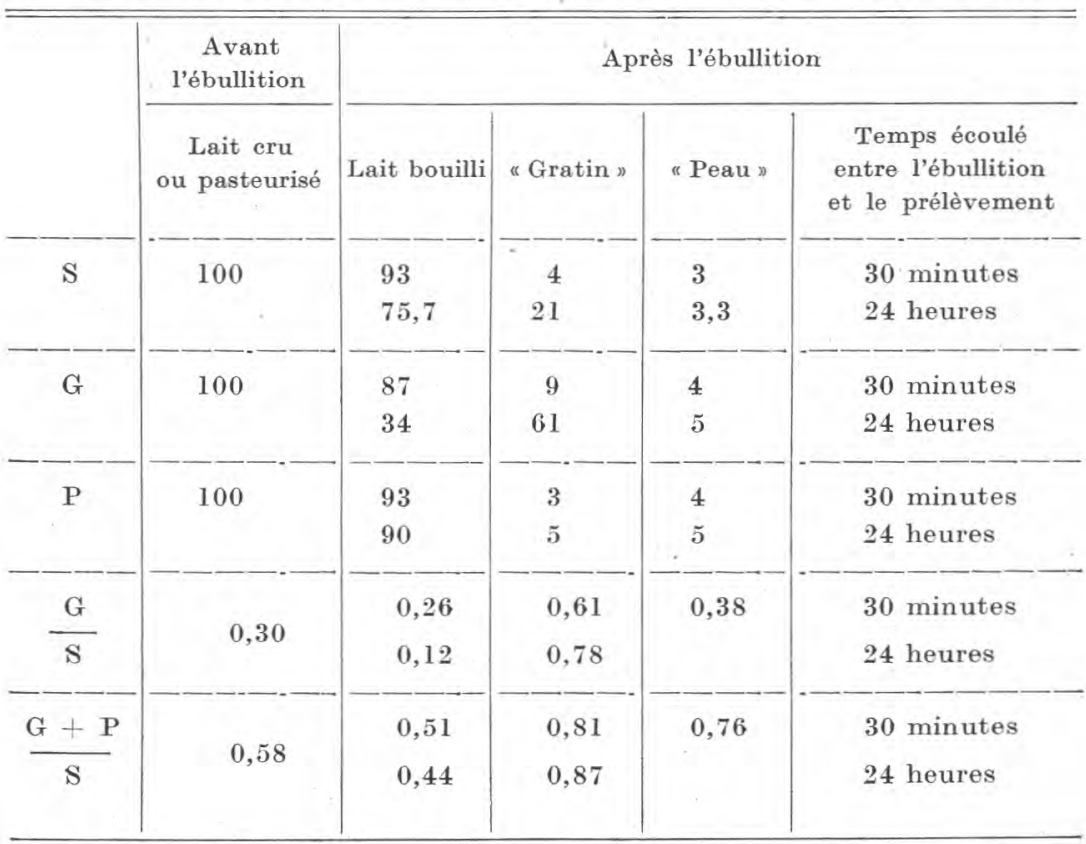
S : matière sèche
G : matière grasse
$\mathbf{P}:$ protéines

\section{C. - Discussion}

La proportion de matière grasse du lait qui passe dans la peau varie dans de larges limites suivant le temps écoulé entre l'ébullition et le prélèvement : au bout de trente minutes, elle est déjà de $9 \%$ et atteint $61 \%$ au bout de vingt-quatre heures. Il en résulte que les personnes qui retirent la peau du lait longtemps après l'avoir fait bouillir consomment, en fait, un lait écrémé. La proportion de matière grasse contenue dans le "gratin" ne varie pas beaucoup pendant la conservation, mais elle n'est jamais négligeable. Au total $66 \%$ des matières grasses peuvent être perdues dans certaines conditions de conservation et d'utilisation du lait $(9 \%$ des consommateurs jettent la peau) à la suite de l'ébullition domestique.

Les proportions de matière sèche et de protéines contenues dans la peau et le gratin sont moins importantes, mais représentent cependant $7 \%$ de la matière sèche et des protéines totales trente minutes après l'ébullition et atteignent respectivement $24 \%$ et 
$10 \%$ si le lait est laissé au repos pendant vingt-quatre heures après l'ébullition.

Pour un poids déterminé de lait cru ou pasteurisé mis en œuvre, la quantité totale d'éléments nutritifs retrouvés dans le poids de lait bouilli obtenu est sensiblement réduite par rapport à celle existant dans le lait initial. Le tableau IV montre en outre que les rapports $\frac{\text { matière grasse }}{\text { matière sèche }}$ et $\frac{\text { matière grasse + protéines }}{\text { matière sèche }}$ sont plus petits dans le lait bouilli que dans le lait cru et qu'ils sont au contraire plus élevés dans la "peau " et dans le "gratin ".

Les techniques domestiques ne permettent guère d'éviter la formation de gratin. Pour réduire la formation de la peau, il faut chauffer le lait juste avant l'emploi et ne pas prolonger inutilement l'ébullition. On économise par ce procédé un deuxième chauffage au moment de la consommation.

L'ébullition est donc une technique onéreuse; de plus il est impossible de chiffrer les pertes dues aux débordements qui se produisent au moment de la montée du lait. Enfin, les calories nécessaires au chauffage, le temps passé au nettoyage de la casserole élèvent encore le prix réel de l'ébullition.

FLORE MICROBIENNE DU LAIT BOUILLI

ET SON EVOLUTION AU COURS DE LA CONSERVATION

\section{A. - Observations préliminaires}

Si l'on chauffe du lait dans une casserole du type déjà décrit et si l'on observe la température indiquée par un thermomètre plongé au centre du liquide, on constate qu'il se forme un léger anneau de mousse le long des parois chaudes de la casserole quand la température atteint $80^{\circ}$. Cette mousse s'épaissit d'abord lentement, puis plus vite : à $90^{\circ}$ elle couvre la surface du lait, à $95^{\circ}$ elle s'épaissit rapidement, à $97^{\circ}$ le lait commence à monter et il se «sauve» à $99^{\circ}(1),(2)$.

Le phénomène ainsi décrit est d'apparence banale. Cependant l'expérience montre que de nombreuses personnes ont sur ce sujet des idées erronées : la plupart des traités d'hygiène, les manuels de puériculture et les articles de revues spécialisées indiquent souvent que le lait "monte", "se sauve", ou même "bout" à $80^{\circ}$,

(1) La différence entre les températures indiquées par des thermomètres plongés dans les différentes parties de la masse du liquide (au fond, à la surface) n'excède pas $1^{\circ}$.

(2) Ces résultats sont obtenus sous une pression atmosphérique normale de 760 millimètres de mercure. Rappelons que pour des températures atmosphériques moyennes, l'eau bout à $100^{\circ}$ à l'altitude 0 , pression 760 millimètres, à $98^{\circ} 3$ à 500 mètres, pression 715 millimètres, à $96^{\circ} 6$ à 1.000 mètres, pression 672 millimètres. 
$85^{\circ}$ ou $90^{\circ}$, et qu'en conséquence il faut prolonger l'ébullition pour assurer la destruction des germes pathogènes.

Puisque la mousse apparaît seulement lorsque le lait atteint $80^{\circ}$ c'est-à-dire une température à laquelle le bacille tuberculeux est détruit (1), il n'y a aucune utilité à prolonger l'ébullition pour assurer la destruction des pathogènes.

Cependant des germes microbiens sporulés résistent à l'ébullition. Sont-ils capables dans les conditions de la pratique ménagère de se développer dans le lait bouilli et de l'altérer?

On a vu d'après les résultats de l'enquête exposés dans la première partie de ce travail que de nombreuses personnes conservent leur lait d'un jour à l'autre, sans toujours prendre des précautions spéciales concernant le refroidissement. Nous avons done cherché à estimer la population microbienne d'un lait du commerce bouilli, puis du même lait conservé aux températures usuelles des habitations.

\section{B. - Population microbienne d'un lait après ébullition et après incubation à différentes températures}

1o Matériel et MÉthode

Le lait utilisé a été acheté chez douze commerçants différents, cru ou pasteurisé, livré en bidons ou en bouteilles.

Pour dénombrer les spores immédiatement après l'ébullition, deux techniques, différant seulement par les modalités du chauffage, ont été concurremment utilisées sur les premiers échantillons examinés. Dans l'une le lait est pipetté directement dans la casserole, après chauffage jusqu'à la température de montée du lait (97-99º), puis il est introduit dans quatre boîtes de Pétri ( $1 \mathrm{~cm}^{3}$ par boîte) et le milieu gélosé est aussitôt coulé sur le lait (2). L'autre technique est une adaptation de celle décrite par RIDGW AY [6] : 10 centimètres cubes de lait sont introduits dans deux tubes à essai identiques et les tubes sont plongés dans un bain-marie bouillant. Ưn thermomètre est placé dans l'un des tubes. On compte deux minutes après le moment où la température atteint $9^{\circ} 5$, puis on plonge les tubes dans l'eau froide. Le lait est alors introduit dans quatre boîtes de Pétri ( $1 \mathrm{~cm}^{3}$ par boîte) comme dans la première méthode. Dans les

(1) Le bacille tuberculeux, aux concentrations auxquelles on peut le rencontrer dans le lait, est détruit par un chauffage à $72^{\circ}$, pendant 15 seeondes ou par un chauffage à $76^{\circ}$ pendant 2 à 4 secondes $(1,5,20)$.

(2) Composition du milieu : extrait de viande : 10 ; peptone : 10 ; C1Na : 5 ; agar : 28 ; eau distillée : 1.000 .

La concentration élevée en gélose, qui rend le milieu « dur " retarde l'envahissement de la surface de la boite par les colonies de sporulés. 
deux techniques les boîtes de Pétri sont incubées quarante-huit heures à $30^{\circ}$. Les résultats obtenus sur les premiers échantillons examinés étant sensiblement équivalents, la méthode de RIDGWAY a seule été retenue par la suite, les conditions du chauffage y étant mieux définies.

La numération des germes du lait bouilli puis incubé est faite dans les conditions suivantes : le lait est mis à bouillir dans une casserole munie d'un couvercle bien ajusté. On arrête le chauffage au moment de la montée du lait ou seulement après dix minutes comptées à partir de cette montée.

La casserole de lait est alors refroidie rapidement jusqu'aux environs de la température d'incubation par immersion dans un courant d'eau. Elle est mise ensuite à incuber pendant vingt-quatre heures. La numération est faite, après dilution convenable, sur le milieu gélosé en boîtes de Pétri.

Les températures d'incubation choisies sont $15^{\circ}, 18^{\circ}$ et $24^{\circ}$. La température de $24^{\circ}$ est celle des habitations en été; elle est habituellement utilisée pour les épreuves de conservation du lait; $18^{\circ}$ est la température normale des locaux habités; $15^{\circ}$ la température d'un local frais ou d'une cave.

\section{Résultats et Discussion}

a) Nombre de germes dans le lait après ébullition.

Nous avons trouvé, pendant les mois de septembre et octobre (tableau V) 22 spores par centimètre cube de lait en moyenne sur 32 échantillons (minimum : moins d'une spore par centimètre cube; maximum : 46 spores par centimètre cube).

Au mois de janvier, la moyenne de 20 échantillons de lait était de 44 spores par centimètre cube, avec un minimum de 10 spores et un maximum de 200. Nos résultats concordent avec ceux de RIDGWAY [6] qui constate des variations saisonnières, avec des chiffres de spores de moins de 1 à plus de 500 par centimètre cube. Il n'y a pratiquement pas de lait exempt de spores ; la pasteurisation et le conditionnement ne modifient pas de façon significative le nombre de spores existant à l'origine dans le lait cru.

b) Nombre de germes dans le lait bouilli après vingt-quatre heures d'incubation.

Le tableau V montre qu'il n'y a pratiquement pas de prolifération microbienne dans le lait bouilli conservé à $15^{\circ}$. La prolifération qui est faible à $18^{\circ}$ devient très importante à $24^{\circ}$; le nombre de germes mierobiens atteint plusieurs millions en vingt-quatre heures. Dans le lait bouilli 10 minutes il y a, en général, moins de germes que dans le lait bouillu pendant un temps plus court. 
TABLEAU V

NOMBRE DE SPORES DANS 32 ÉCHANTILLONS DE LAIT AUSSITOT APRÈS L'ÉBULLITION NOMBRE DE GERMES ET COAGULATION A L'ALCOOL APRÉS INCUBATION DE 24 HEURES A DIFFÉRENTES TEMPÉRATURES

\begin{tabular}{|c|c|c|c|c|c|c|c|}
\hline \multirow{3}{*}{$\begin{array}{l}\text { Numéros } \\
\text { des } \\
\text { échan- } \\
\text { tillons }\end{array}$} & \multicolumn{2}{|c|}{$\begin{array}{l}\text { Nombre de spores } \\
\text { après ébullition }\end{array}$} & \multirow{3}{*}{$\begin{array}{c}\text { Tempé- } \\
\text { rature } \\
\text { d'incu- } \\
\text { bation }\end{array}$} & \multicolumn{4}{|c|}{ Après incubation de 24 heures } \\
\hline & \multirow{2}{*}{$\begin{array}{c}\text { Technique } \\
1\end{array}$} & \multirow{2}{*}{$\mid \begin{array}{c}\text { Technique } \\
2\end{array}$} & & \multicolumn{2}{|c|}{ Lait chauffé jusqu'à montée } & \multicolumn{2}{|c|}{ Lait bouilli 10 minutes } \\
\hline & & & & $\begin{array}{c}\text { Nombre } \\
\text { de germes }\end{array}$ & $\begin{array}{l}\text { Coagulat. } \\
\text { à l'alcool }\end{array}$ & $\begin{array}{l}\text { Nombre } \\
\text { de germes }\end{array}$ & $\begin{array}{r}\text { Coagulat. } \\
\text { à l'alcool } \\
\end{array}$ \\
\hline 1 & & 41 & & 43 & - & & \\
\hline 2 & & 27 & & 37 & & & \\
\hline 3 & s & 19 & $15^{\circ}$ & 40 & & & \\
\hline 4 & & 18 & & 37 & & & \\
\hline 5 & & 14 & & 35 & & & \\
\hline 6 & . & 28 & & 30 & & & \\
\hline \multicolumn{2}{|c|}{ moyennes } & 24,5 & & 37 & & & $\cdot$ \\
\hline 7 & & 28 & & $38.10^{3}$ & & . & \\
\hline 8 & & 36 & & $28.10^{3}$ & & & \\
\hline 9 & & 16 & & $30.10^{3}$ & & & \\
\hline 10 & & 25 & & $32.10^{3}$ & & & \\
\hline 11 & & 14 & $18^{\circ}$ & $32.10^{3}$ & & & \\
\hline 12 & & 31 & & $0,27.10^{3}$ & & & \\
\hline 13 & & 9 & & $0,26 \cdot 10^{3}$ & & & \\
\hline 14 & & 14 & & $0,27.10^{3}$ & & & \\
\hline \multicolumn{2}{|c|}{ moyennes } & 21,6 & & $20.10^{3}$ & & & \\
\hline 15 & 0 & 0 & & $0,4.10^{6}$ & & $0,001.10^{6}$ & 8 \\
\hline 16 & 9 & 7 & & $9.10^{6}$ & & $0,16.10^{6}$ & \\
\hline 17 & 7 & 5 & & $0,1.10^{6}$ & & & \\
\hline 18 & 25 & 23 & & $4,3.10^{6}$ & & $2,6.10^{6}$ & \\
\hline 19 & 25 & 28 & 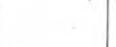 & $5,5.10^{6}$ & & $0,04.10^{6}$ & \\
\hline 20 & 29 & 30 & & $1,7.10^{6}$ & & $2,5.10^{6}$ & \\
\hline 21 & 4 & 5 & & $0,5 \cdot 10^{6}$ & - & $2,8.10^{6}$ & - \\
\hline 22 & 18 & 15 & $24^{\circ}$ & $6,7.10^{6}$ & + & $3.10^{6}$ & 一 \\
\hline 23 & 32 & 29 & . & $4,5.10^{6}$ & + & $2.10^{6}$ & - \\
\hline 24 & & 12 & & $2,5.10^{6}$ & + & $4,4.10^{6}$ & + \\
\hline 25 & & 13 & & $8,4.10^{6}$ & + & $0,01.10^{6}$ & 一 \\
\hline 26 & . & 24 & & $13.10^{6}$ & + & & - \\
\hline 27 & & 10 & & $4,4.10^{6}$ & - & $0,1.10^{6}$ & 一 \\
\hline 28 & & 46 & & $7,2.10^{6}$ & + & $3,5.10^{6}$ & - \\
\hline 29 & & 36 & & $1,1.10^{6}$ & - & $0,001.10^{6}$ & - \\
\hline 30 & & 20 & & $7,6.10^{6}$ & & $0,5.10^{6}$ & \\
\hline 31 & & 12 & & $8,3.10^{6}$ & & $1,9.10^{6}$ & \\
\hline 32 & & 10 & & $5.10^{6}$ & & $2,2.10^{6}$ & \\
\hline \multicolumn{2}{|c|}{ moyennes } & 17,9 & & $5,5.10^{6}$ & & $1,6.10^{6}$ & \\
\hline
\end{tabular}


Ce n'est cependant pas toujours le cas : une ébullition prolongée favorise parfois la prolifération microbienne (voir par exemple les échantillons no $20,21,24$ du tableau $V$ ).

\section{C. - Altérations du lait bouilli et conservé à $24^{\circ}$}

Sur un certain nombre d'échantillons étudiés au paragraphe précédent, nous avons effectué l'épreuve de coagulation à l'alcool à $68^{\circ}$. On sait que la coagulation du lait à l'alcool correspond à un état d'instabilité de la caséine résultant soit de la formation d'une certaine quantité d'acide lactique dans le lait, soit d'un début de protéolyse de la caséine elle-même, soit des deux phénomènes réunis.

Le tableau V montre que de nombreux échantillons coagulent après vingt-quatre heures d'incubation à $24^{\circ}$. Nous verrons plus loin l'importance de ce fait : la coagulation à l'alcool peut être utilisée comme épreuve de conservation du lait bouilli,

\section{D. - Nature des germes résistant à l'ébullition}

\section{Méthode}

Huit échantillons de deux litres de lait du commerce ont été divisés en deux portions : l'une des portions était simplement portée à l'ébullition tandis que l'autre était maintenue à l'ébullition pendant dix minutes. Le lait de chacune des portions était ensuite réparti en flacons stériles et ceux-ci incubés à $30^{\circ}$ jusqu'à altération visible, c'est-à-dire pendant 1 à 15 jours.

Plusieurs groupes d'échantillons ont alors été constitués selon l'aspect de l'altération. Dans chaque groupe, on a isolé et identifié les germes donnant des colonies d'aspects différents, sur gélose nutritive en aérobiose ou sur gélose VF en anaérobiose.

Les anaérobies ont été identifiés selon les méthodes classiques en se basant sur les caractères suivants : morphologie, mobilité, aspect des colonies, vitesse de culture, abondance des gaz, altérations $\mathrm{du}$ lait, production de $\mathrm{H}_{2} \mathrm{~S}$ et d'indol ; fermentation du saccharose, de l'amidon, de la glycérine et de la mannite.

Les aérobies ont été étudiés selon la méthode décrite par Sмiтh et al. [7], et par KNIGHT et Proom [8] et identifiés d'après les caractères suivants : morphologie, position de la spore, aspect des colonies sur gélose nutritive et sur gélose à $p \mathrm{H} 9,6$; action sur le glucose, l'arabinose, le xylose et l'amidon; utilisation du citrate et de l'urée; production de lécithinase, caractères d'aérobiose. 


\section{$2^{\circ}$ Résultats et Discussion}

a) Deux échantillons ont présenté dans tous les flacons, quelle que soit la durée de l'ébullition, un aspect caractérisé par une digestion gazeuse rapide apparaissant entre la $12^{\mathrm{e}}$ et la $48^{\mathrm{e}}$ heure d'incubation. Nous avons isolé de tous les flacons Welchia perfringens en culture pure.

b) Dans tous les autres flacons, les altérations ont présenté les aspects suivants : coagulation ou absence de coagulation; digestion plus ou moins rapide du caillot laissant exsuder un liquide jaune ou protéolyse en surface et dépôt d'un sédiment blanc au fond $\mathrm{du}$ flacon. De chaque flacon, nous avons isolé au maximum deux espèces de sporulés aérobies. Sur 18 germes identifiés, nous avons trouvé dix fois Bacillus licheniformis; les autres germes sont Bacillus cereus, Bacillus subtilis, Bacillus pumilus, Bacillus circulans.

c) Les germes que nous avons isolés et identifiés sont les mêmes que ceux identifiés par de nombreux auteurs, au cours de travaux concernant soit l'hygiène du lait cru, soit la flore des laits dits "stérilisés ».

Paquet et GaUvin [9] trouvent Clostridium perfringens (Welchia perfringens) dans $18,3 \%$ des laits pasteurisés canadiens qu'ils ont examinés. Buttiaux et Benrens [10] trouvent le même germe dans $16 \%$ des laits pasteurisés mis en vente dans le commerce dans les départements du nord de la France.

Les sporulés aérobies ont surtout été étudiés dans le lait «stérilisé ". SMith, Gordon et Clark [7] identifient 230 germes, qui sont : $B$. subtilis et $B$. licheniformis, $204 ; B$. pumilus, $10 ;$ B. coagulans, 8 ; $B$. megatherium, 4 ; B. cereus, 2 ; B. mycoüdes, 1 ; B. laterosporus, 1 ; de leur côté Grinsted et ChegG [11] isolent du lait stérilisé à l'usine ou au laboratoire, B. subtilis, 68 ; B. licheniformis, 190 ; B. pumilus, 2 ; B. circulans, $10 ;$ B. brevis, 31 ; et B. macerans, 4. Galesloot [21] trouve dans les laits pasteurisés au laboratoire à différentes températures : B. cereus, B. megatherium, B. subtitis, B. pumilus, B. circulans.

\section{E. - Vitesse de développement des sporulés dans le lait bouilli}

Nous avons vu que du lait bouilli conservé à $24^{\circ}$ contient après vingt-quatre heures un nombre souvent très élevé de microorganismes. Mais ce nombre est variable d'un échantillon de lait à l'autre même lorsque ces échantillons de lait contiennent à l'origine, aussitôt après l'ébullition, un nombre de spores assez voisin. Ainsi 
que nous l'avons vu, le nombre de germes après incubation est en général plus bas lorsque l'ébullition a duré longtemps. Mais on trouve cependant aussi le phénomène inverse : ceci peut s'expliquer soit par une thermo-résistance différente des espèces microbiennes présentes dans le lait (certaines espèces peu sensibles n'étant pas détruites par l'ébullition tandis que d'autres subissent une destruction proportionnelle à le durée du chauffage), par soit une modification de la vitesse de croissance des microorganismes dans le lait à la suite d'un chauffage plus ou moins prolongé de celui-ci [17].

Nous avons vu aussi qu'une proportion élevée des laits bouillis conservés vingt-quatre heures coagulent à l'alcool. On peut se demander quelle signification attribuer à ce caractère; en effet, dans un lait cru la coagulation à l'alcool apparaît en général à partir d'une certaine acidité et marque un stade de la fermentation lactique, sans signification hygiénique particulière; au contraire, dans le lait bouilli, qui ne subit pas la fermentation lactique, le moment d'apparition de la coagulation correspond à un stade de dégradation des substances azotées qu'il est intéressant, du point de vue de l'hygiène, de préciser.

Dans cette partie de notre travail nous avons étudié la thermorésistance de quelques-uns des sporulés isolés du lait pour déterminer l'influence qu'une ébullition prolongée peut avoir sur eux. Nous avons mesuré leur croissance dans le lait bouilli et leur action sur les différents constituants du lait mesurée par la protéolyse de la caséine, par les variations du $p H$ et par la stabilité du lait à l'alcool.

\section{Méthodes}

Pour travailler dans des conditions bien déterminées et reproductibles, et obvier aux difficultés expérimentales provenant d'un développement plus ou moins rapide des sporulés présents dans les échantillons de lait du commerce, il faut partir d'un lait dont la flore sporulée est connue. La meilleure méthode est celle qui consiste à ensemencer un lait propre, très pauvre en spores, avec un nombre connu de spores de l'espèce à étudier.

a) Préparation et titrage des suspensions de spores de germes aérobies.

Trois germes, isolés des essais précédents, ont été utilisés. Ce sont : Bacillus cereus C J 1, Bacillus subtilis S J 2, Bacillus licheniformis $\mathrm{L} J \overline{\mathrm{J}}$.

Plusieurs tubes de gélose nutritive sans peptone (1) sont ensemencés abondamment à partir d'une culture de vingt-quatre heures en bouillon. Après huit jours d'incubation à $30^{\circ}$ la surface de la

(1) Composition du milieu : extrait de viande 10 ; ClNa 5 ; gélose 15 ; eau 1.000. 
gélose est râclée et les germes sont mis en suspension dans une solution tamponnée (1).

La suspension obtenue est filtrée stérilement sur papier Chardin, chauffée à $80^{\circ}$ pendant dix minutes pour détruire les formes végétatives, puis conservée à $+4^{\circ}$. Le titrage est effectué par numération sur boîtes de Pétri en utilisant le milieu nutritif gélosé indiqué plus haut; la lecture est faite après 24 heures (B. cereus) ou 48 heures (B. subtilis et $B$. licheniformis) d'incubation à $30^{\circ}$. Le titre de la suspension est alors ramené à 100.000 spores par centimètre cube. Le titre est resté constant au cours de six mois d'observation.

b) Mesure de la thermo-résistance des spores de germes aérobies du lait.

Du lait cru recueilli aseptiquement est ensemencé avec la suspension de spores de façon à obtenir environ 100 spores au centimètre cube (2) puis il est réparti en tubes de $18 \times 180$. Ceux-ci sont plongés dans un bain-marie réglé à $80^{\circ}, 90^{\circ}$ ou $100^{\circ}$ pendant un temps plus ou moins long compté à partir du moment où la température marquée par un thermomètre placé dans un tube témoin indique $78^{\circ}, 88^{\circ}$ ou $97^{\circ} 5$.

Les tubes sont aussitôt refroidis et la numération est faite suivant la technique déjà décrite.

c) Préparation et titrage des suspensions de spores de germes anaérobies.

La sporulation de $W$. perfringens a rarement lieu en culture ; nous avons utilisé à sa place un germe anaérobie souvent rencontré dans le lait Clostridium sporogenes souche $\mathrm{Cl3}$.

La culture est faite en bouillon glucosé dans un ballon rempli jusqu'au col. Après huit jours d'incubation à $30^{\circ}$, on filtre sur papier Chardin pour éliminer les agglomérats de germes; puis on lave trois fois dans la solution tamponnée en recueillant les spores par centrifugation. La suspension est chauffée à $80^{\circ}$ pendant dix minutes puis conservée à $+4^{\circ}$. Le titrage de la suspension est fait par la méthode des dilutions de McCrady en utilisant le milieu de Hirsch

(1) Formule C de Butterfield.

$\mathrm{PO}_{4} \mathrm{H}_{2} \mathrm{~K} 34 \mathrm{gr}$. dans $500 \mathrm{~cm}^{3}$ ajuster à $p \mathrm{H} 7,2$ par $\mathrm{NaOH}$ et compléter à 1 litre solution précédente de phosphate ....... $1,25 \mathrm{~cm}^{3}$

$\mathrm{Cl}_{2} \mathrm{Ca}, \quad 4 \mathrm{H}_{2} \mathrm{O} \quad 0,1 \quad \mathrm{M} \ldots \ldots \ldots \ldots \ldots \ldots . .2,5 \mathrm{~cm}^{3}$

$\mathrm{Cl}^{3} \mathrm{Fe}, \quad 6 \mathrm{H}_{2} \mathrm{O} \quad 0,001 \mathrm{M} \ldots \ldots \ldots \ldots \ldots . \ldots \ldots, 0,5 \mathrm{~cm}^{3}$

$\mathrm{SO}_{4} \mathrm{Mg}, 7 \mathrm{H}_{2} \mathrm{O} \quad 0,04 \quad \mathrm{M} \ldots \ldots \ldots \ldots \ldots \ldots . .2,5 \mathrm{~cm}^{3}$

Eau distillée .................... $1.000 \mathrm{~cm}^{3}$

(2) C'est-à-dire un nombre voisin de celui trouvé dans les laits du commerce. 
et Grinsted (1) [18] en tubes de Hall remplis jusqu'à l'étranglement. La lecture est faite après quarante-huit heures d'incubation à $30^{\circ}$. La suspension obtenue titre 45.000 spores par centimètre cube.

\section{d) Ebullition et incubation.}

Le lait cru est ensemencé (généralement avec 100 spores par centimètre cube) et mis à bouillir puis réparti dans des flacons de 150 centimètres cubes à raison de 100 centimètres cubes par flacon. Ceux-ci sont aussitôt placés au bain-marie à $24^{\circ}$ et dans certains cas à $18^{\circ}$. Chaque flacon ne sert que pour un seul prélèvement.

e) Etablissement des courbes de croissance.

Des numérations sont effectuées en prélevant à intervalles réguliers un flacon dans le bain-marie. La numération des germes aérobies est faite par la méthode des dilutions et culture sur milieu gélosé en boîte de Pétri. On utilise le même milieu que pour le titrage des suspensions de spores; la lecture est faite après vingtquatre ou quarante-huit heures d'incubation à $30^{\circ}$.

Les anaérobies sont dénombrés par la méthode de BREED par examen direct sur lame.

f) Coagulation à l'alcool et mesure $d u p \mathrm{H}$.

2 centimètres cubes de lait sont additionnés de 2 centimètres cubes d'alcool à $68^{\circ}$ neutralisé et additionné de pourpre de bromocrésol. On observe la présence ou l'absence de coagulation.

La mesure du $p \mathrm{H}$ est faite avee une électrode de verre.

g) Mesure de la protéolyse par titrage de l'azote soluble.

Les protéines du lait sont précipitées par l'acide trichloracétique selon la méthode de Rowland [12] et l'azote du filtrat est dosé au Kjeldahl.

\section{2o Résultats}

a) Thermo-résistance.

Les courbes des figures 1 et 2 expriment le comportement des spores au cours de l'ébullition du lait. Alors que les spores de $B$. cereus et de $B$. licheniformis subissent une destruction importante, celles de $B$. subtilis non seulement résistent à l'ébullition mais voient encore leur germination activée par un chauffage prolongé à la température d'ébullition du lait.

On remarque sur la figure 2, qu'il faut un temps de maintien minimum de vingt minutes à $100^{\circ}$ pour obtenir le nombre maximum

(1) Composition du milieu : extrait de viande 10 ; peptone 10 ; acétate de sodium 5 ; extrait de levure 3 ; amidon soluble 1 ; cystéine 0,5 ; glucose 10 ; eau 1.000 . 
de colonies de $B$. subtilis sur gélose et qu'il faut maintenir plus d'une heure la température à $80^{\circ}$ ou $90^{\circ}$ pour obtenir le même effet d'activation.

Il est probable que de nombreuses autres souches de sporulés présentent le même comportement que la souche de B. subtilis,

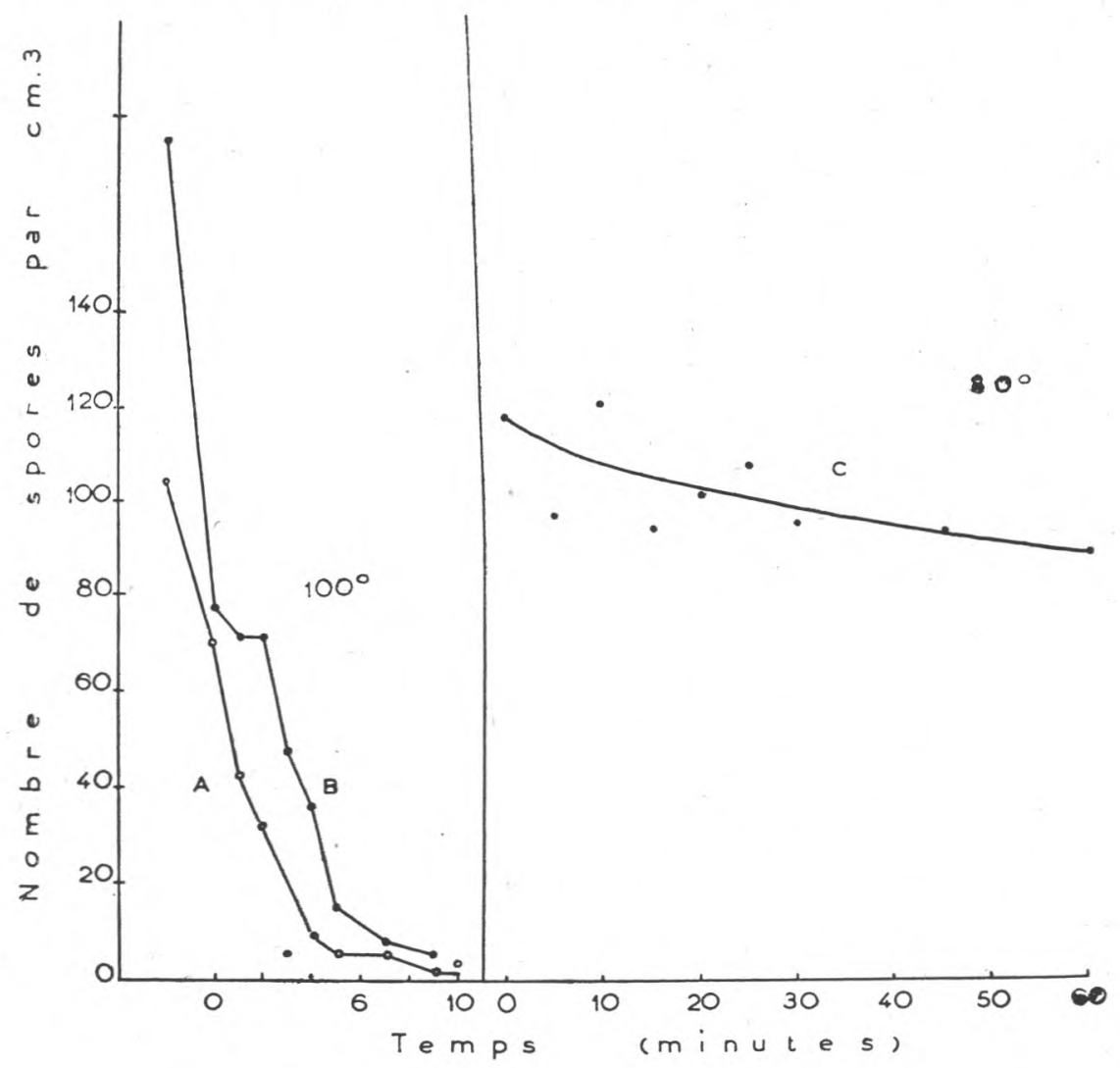

Fig. 1. - Action de la chaleur sur les spores de B. lichenijormis (A) et de B. cereus (B et C) à $100^{\circ}$ et à $80^{\circ}$.

S. J. 2. La présence de tels germes dans le lait explique alors pourquoi certains échantillons (échantillons 20, 21, 24, du tableau V) s'altèrent d'autant plus vite qu'ils ont bouilli plus longtemps.

b) Croissance et altération du lait par B. cereus (fig. 3 et 4).

La croissance de $B$. cereus dans le lait est très rapide. Un lait renfermant 100 spores par centimètres cubes et maintenu à l'ébullition pendant une à dix minutes contient, après une conservation 
de vingt-quatre heures à $\mathbf{2 4}^{\circ}$, dix millions de germes par centimètre cube. Conservé à $18^{\circ}$ il lui faut quarante-huit heures pour atteindre le même chiffre.

Une prolongation de l'ébullition du lait ne modifie pas sensiblement la vitesse de croissance de $B$. cereus mais, en réduisant le nombre de spores capables de germer, elle augmente la durée

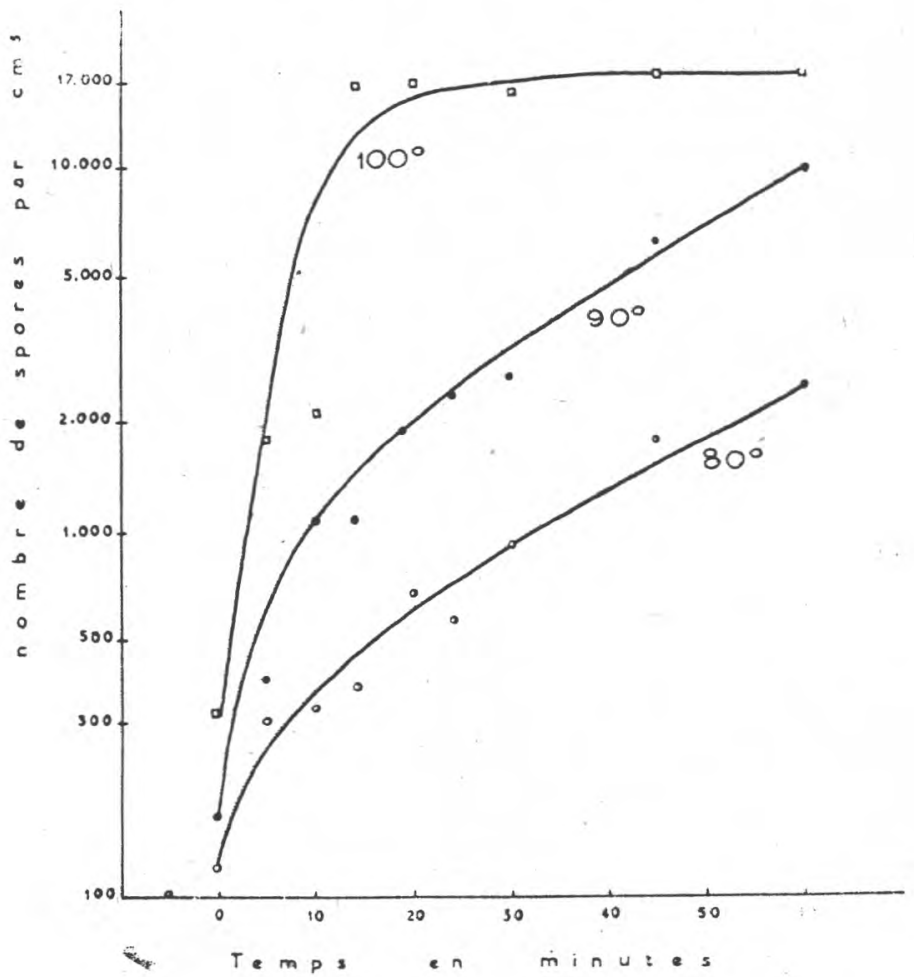

Fig. 2. - Action de la chaleur sur les spores de B. subtilis. Activation par la chaleur de la germination.

de conservation du lait. Si l'on prend comme limite de conservation le moment où le lait coagule à l'alcool, un lait bouilli moins d'une minute se conserve moins de dix-huit heures à $24^{\circ}$.

Il n'y a pas de variation sensible du $p H$ du lait au cours de cette période. Le phénomène de coagulation par l'alcool se produit vers la fin de la phase exponentielle de croissance ; il paraît lié à la protéolyse de la caséine puisqu'on observe la coagulation à l'alcool au moment où cette protéolyse devient mesurable (fig. 3). Le point où la protéolyse de la caséine devient mesurable peut aussi être 


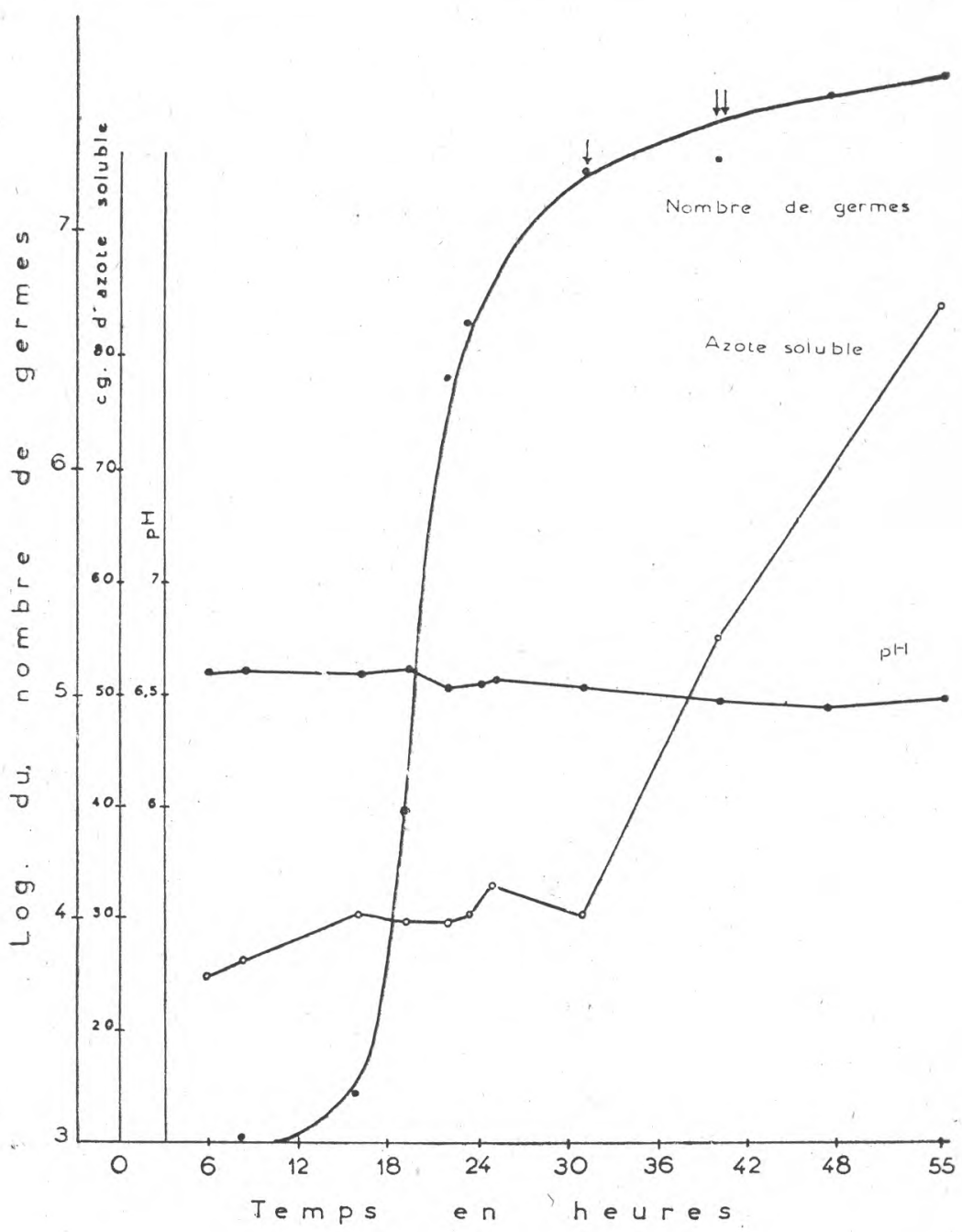

Fig. 3. - Croissance de B. cereus dans le lait bouilli 10 minutes (log. du nombre de germes par $\mathrm{cm}^{3}$ ). Ensemencement : 100 spores par $\mathrm{cm}^{3}$; température d'incubation : $24^{\circ}$. Variations du taux d'azote soluble (centigrammes d'azote par litre) et du $p H$.

$\downarrow \downarrow$ Coagulation spontanée, $\quad \downarrow$ coagulation à l'alcool.

considéré comme le début de la putréfaction et représente donc le moment où le lait bouilli doit être jugé impropre à la consommation. La coagulation du lait à l'ébullition ou même la coagulation à la température ambiante, qui limitent en pratique la conservation 


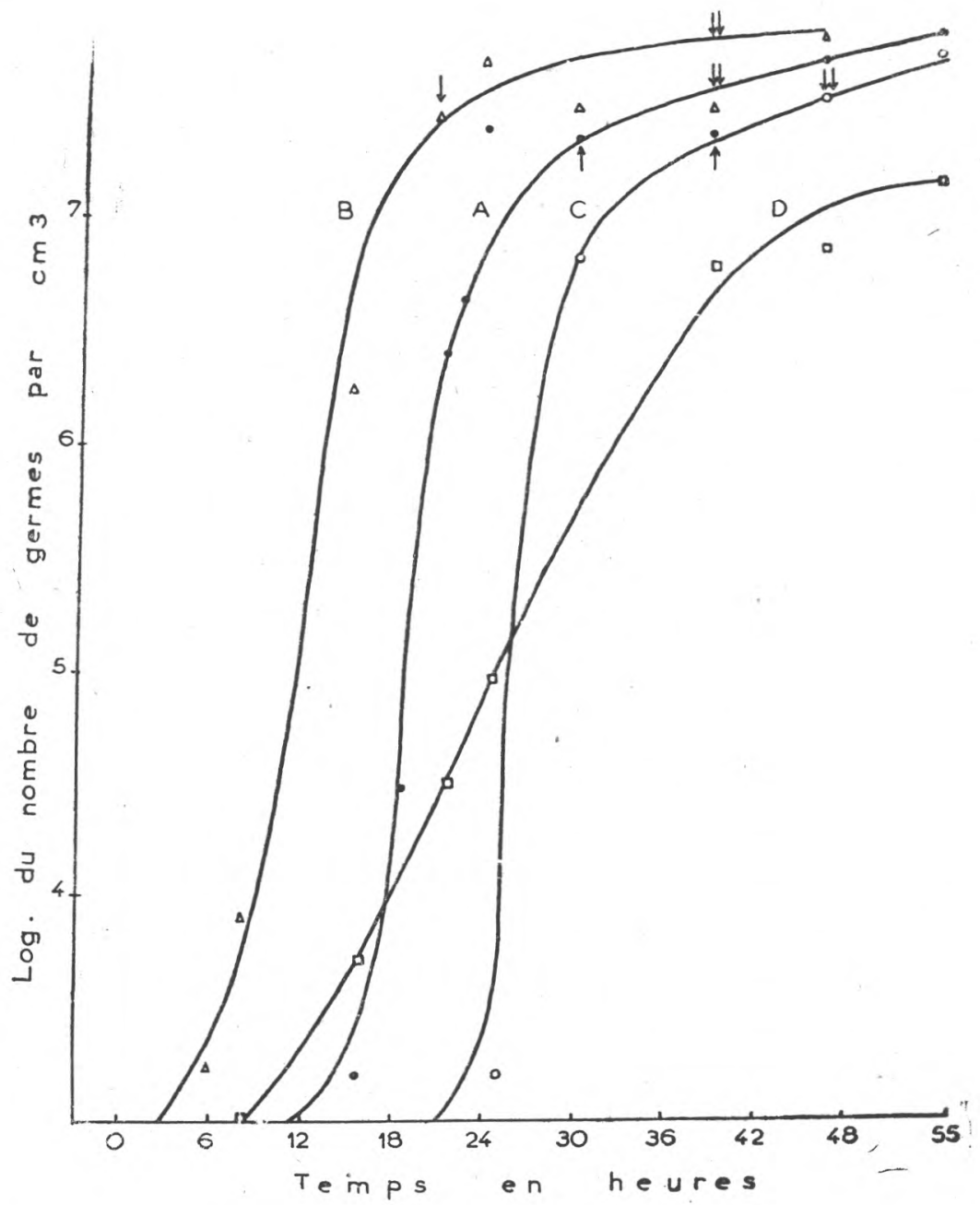

Fig. 4. - Croissance de B. cereus dans le lait bouilli (log. du nombre de germes par $\mathrm{cm}^{3}$ ). A : ensemencement : 100 spores par $\mathrm{cm}^{3}$; ébullition : 10 minutes ; incubation : $24^{\circ}$. $-\mathrm{B}$ : ensemencement : 100 spores par $\mathrm{cm}^{3}$; ébullition : jusqu'à montée du lait; incubation à $24^{\circ}$. $-\mathrm{C}$ : ensemencement : 10 spores par $\mathrm{cm}^{3}$; ébullition : 10 minutes; incubation à $24^{\circ}$. $-\mathrm{D}$ : ensemencement : 100 spores par $\mathrm{cm}^{3}$; ébullition : 10 minutes; incubation à $18^{\circ}$. $\downarrow$ Coagulation à l'alcool, $\quad \downarrow \downarrow$ coagulation spontanée.

et la consommation du lait, ne se produisent que plusieurs heures plus tard. Au cours de la conservation du lait boulli, il y a donc une période qui précède l'apparition des signes visibles d'altération 


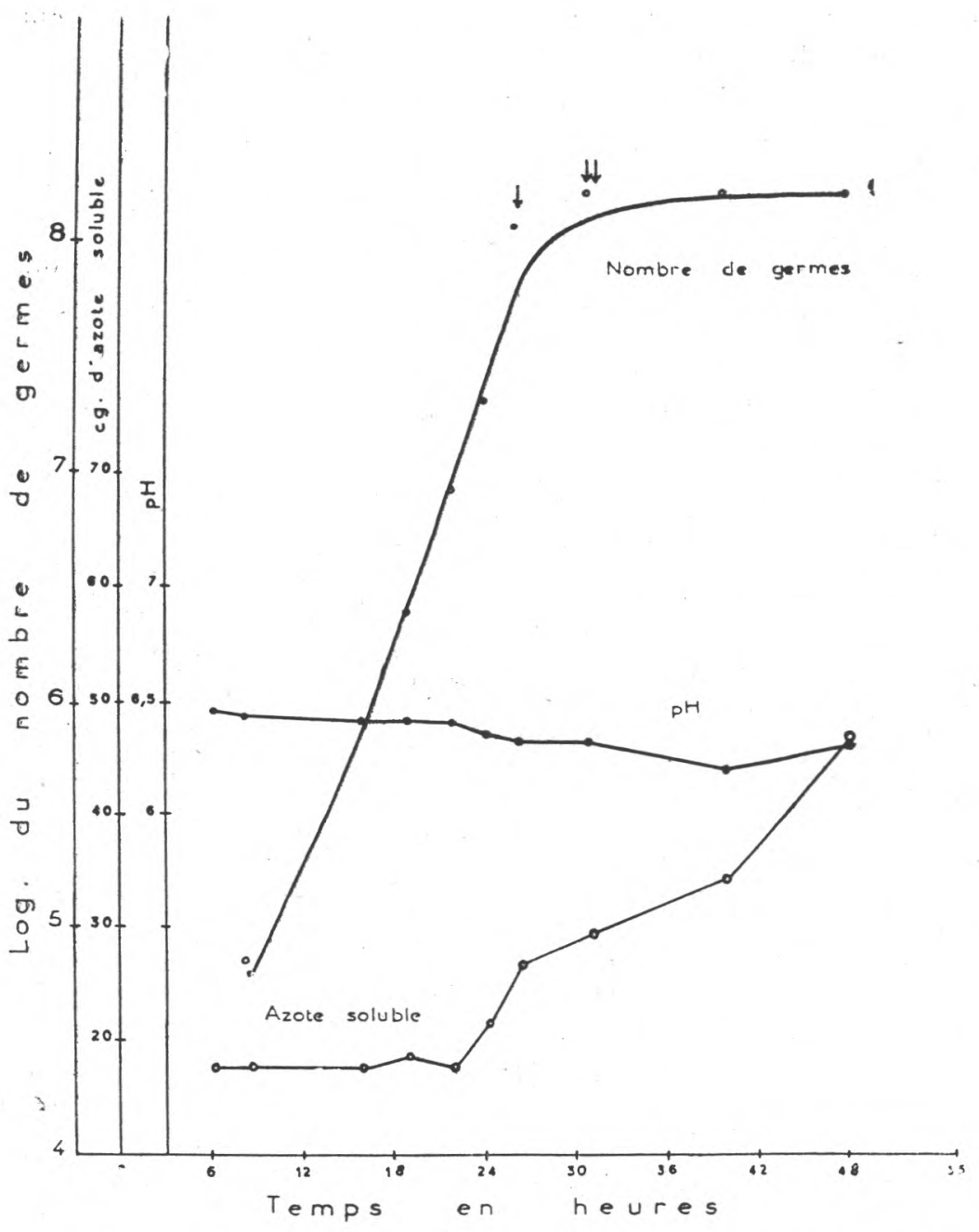

Fig. 5. - Croissance de Cl. sporogenes dans le lait bouilli 10 minutes (log. du nombre de germes par $\mathrm{cm}^{3}$ ); ensemencement : 100 spores; température d'incubation : $24^{\circ}$. Variations du taux d'azote soluble (centigrammes par litre) et du $p H$.

$\downarrow$ Coagulation à l'alcool, $\quad \downarrow \downarrow$ coagulation spontanée.

pendant laquelle le lait, en voie de putréfaction, devrait être rejeté de la consommation. Les résultats de l'enquête exposés dans la première partie de notre travail laissent supposer qu'en fait le lait est souvent consommé à ce stade. Il doit en être ainsi, par exemple, au cours de la saison chaude lorsque le lait est conservé 
pendant plus de vingt-quatre heures sans refroidissement après l'ébullition.

c) Croissance et altération du lait par B. subtilis et B. licheniformis.

$B$. subtilis s'est développé, lui aussi, très vite dans le lait. Toutefois il n'a pas provoqué l'apparition d'altérations visibles pendant la durée de l'expérience (71 heures). La protéolyse débute entre la $40^{\mathrm{e}}$ et la $48^{\mathrm{e}}$ heures. La population microbienne dépasse 1 million en vingt-quatre heures et 100 millions en cinquante-cinq heures.

Les courbes de croissance, établies après l'ébullition de une à dix minutes sont comparables à celle de $B$. cereus, mais en inversant toutefois les positions respectives des courbes A et B (fig. 4) en raison de l'activation de la germination des spores par la chaleur signalée plus haut.

$B$. licheniformis se développe moins bien dans le lait bouilli que $B$. cereus. Quelle que soit la durée de l'ébullition, le temps de latence est de vingt heures à $24^{\circ}$. En vingt-quatre heures à $24^{\circ}$ la population microbienne dépasse 100.000 germes par centimètre cube. En quarante-huit heures elle atteint 10 millions par centimètre cube. Il ne s'est produit dans les conditions de nos expériences (55 heures) ni coagulation à l'alcool, ni coagulation à l'ébullition, ni protéolyse notable.

d) Clostridium sporogenes (fig. 5).

$C l$. sporogenes ne cultive pas dans le lait simplement porté à l'ébullition. Mais il présente, dans le lait bouilli dix minutes, une croissance extrêmement rapide et précoce. Un lait ensemencé avec 100 spores au centimètre cube et maintenu à l'ébullition pendant dix minutes renferme déjà près de 100.000 bactéries au centimètre cube après six heures à $24^{\circ}$; il en renferme 100 millions après vingtsix heures.

La coagulation à l'alcool apparaît vers la $26^{\mathrm{e}}$ heure, peu de temps après le début de la protéolyse, au moment de la phase de croissance maxima : l'odeur caractéristique des cultures de $\mathrm{Cl}$. sporogenes est, à ce moment, perceptible mais peu prononcée.

La durée du chauffage et de l'ébullition ayant une grande influence sur la croissance de $C l$. sporogenes dans le lait, nous avons comparé la population microbienne de plusieurs échantillons de lait conservés à $24^{\circ}$ pendant vingt-deux heures et ayant subi soit une pasteurisation de laboratoire $\left(63^{\circ} 5\right.$ pendant 30 minutes au bainmarie), soit une ébullition de plus ou moins longue durée. Ces échantillons étaient ensemencés à raison de 100 spores environ par centimètre cube avant ou après le chauffage à la température de pasteurisation ou d'ébullition. 
L'ébullition, la répartition et l'incubation du lait ont été faites dans les mêmes conditions que pour les essais précédents.

Les résultats sont indiqués dans le tableau VI.

\section{TABLEAU VI}

INFLUENGE DU GHAUFFAGE SUR LE DÉVELOPPEMENT DE CL. SPOROGENES DANS LE LAIT BOUILLI

\begin{tabular}{|c|c|c|c|}
\hline $\begin{array}{l}\text { Température } \\
\text { de ehauffage }\end{array}$ & $\begin{array}{l}\text { Durée } \\
\text { du chauffage } \\
\text { en minutes }\end{array}$ & $\begin{array}{c}\text { Moment } \\
\text { de l'ensemencement }\end{array}$ & $\begin{array}{l}\text { Nbre de germes } \\
\text { après } 24 \text { heures } \\
\text { à } 24^{\circ} \text { (Breed) }\end{array}$ \\
\hline \multirow{2}{*}{$\begin{array}{c}100^{\circ} \\
\text { (ébullition) }\end{array}$} & $\begin{array}{r}10 \\
7 \\
3 \\
0\end{array}$ & Avant ehauffage & $\begin{array}{r}15.000 .000 \\
750.000 \\
<20.000 \\
<20.000\end{array}$ \\
\hline & $\begin{array}{r}10 \\
0\end{array}$ & Après chauffage & $\begin{array}{l}<20.000 \\
<20.000\end{array}$ \\
\hline $63^{\circ} 5 \mathrm{C}$. pasteurisation & 30 & Avant chauffage & $<20.000$ \\
\hline
\end{tabular}

On peut en déduire que le chauffage a non seulement une action sur le lait lui-même (l'ébullition chasse l'air du lait et rend le milieu réducteur) mais encore sur les spores, probablement en "activant " leur germination. Il paraît légitime de généraliser la première de ces actions à d'autres anaérobies, en particulier à $W$. perfringens dont on sait qu'il est avec $\mathrm{Cl}$. sporogenes un des germes anaérobies le plus souvent rencontrés dans le lait. On voit ainsi qu'une ébullition prolongée du lait, loin d'améliorer les qualités de conservation de celui-ci, peut le rendre plus favorable à la croissance de certains germes sporulés.

Précisons que les mêmes essais, reproduits en laissant le lait dans la casserole pendant l'incubation au lieu de le répartir en flacons, donnent des résultats comparables : la croissance des germes est même encore plus rapide.

\section{$3^{\circ}$ Discussion}

Les germes sporulés aérobies que l'on rencontre habituellement dans tous les laits sont capables de se développer rapidement après l'ébullition et pendant la conservation du lait à température élevée $\left(24^{\circ}\right)$. Ce développement est tel que la putréfaction du lait débute bien souvent avant le délai de vingt-quatre heures qui représente dans beaucoup de cas le délai d'utilisation pratique du 
lait et aussi avant l'apparition des signes visibles d'altération. On sait que la culture de certains sporulés dans le lait conduit à une production de toxines [13] et que des toxi-infections alimentaires dues au lait sont attribuées à $W$. perfringens [14], [15] et à certaines bactéries du genre Bacillus [16]. Si l'on tient compte du fait que de nombreuses personnes conservent le lait bouilli pendant plus de vingt-quatre heures, on est amené à penser que l'ébullition domestique du lait ne donne des garanties hygiéniques sérieuses que si elle est faite dans des conditions bien définies.

Quelles sont ces conditions?

La durée de l'ébullition d'abord : les traités d'hygiène considérant que le lait "monte" à $80^{\circ}$ recommandent souvent une ébullition de trois à dix minutes, temps nécessaire pour atteindre $100^{\circ}$. En fait, tous les laits qu'ils soient traits depuis quelques instants seulement ou à la limite de leur conservation ne "montent" qu'aux environs de $97^{\circ}$. Puisque le bacille tuberculeux, le plus résistant des pathogènes non sporulés, est détruit à $75^{\circ}$ en quelques secondes, il n'y a aucune raison pour prolonger le chauffage après la montée du lait. Prolonger l'ébullition c'est sans doute détruire quelques spores mais aussi en " activer " d'autres et c'est surtout créer dans la casserole elle-même un milieu favorable à la croissance des anaérobies, bien plus redoutables que les aérobies qui cultivent dans un lait bouilli moins longtemps.

La durée de conservation et le refroidissement ensuite : si le lait doit être consommé dans l'heure qui suit l'ébullition il est inutile, au point de vue bactériologique, de le refroidir. Pendant un délai de six heures environ le nombre de bactéries présentes n'augmente que peu ou pas. Mais si le lait doit être conservé plus longtemps il est indispensable de le refroidir et de le maintenir aux environs de $15^{\circ}$ : à cette température, en vingt-quatre heures, les sporulés ne se développent pratiquement pas.

Il est curieux de constater que les recommandations relatives à l'ébullition domestique du lait, souvent largement diffusées par la grande presse, insistent toujours sur la prolongation de l'ébullition, qui est en fait inutile ou même nuisible, mais ne mentionnent que rarement le refroidissement qui est, au point de vue bactériologique, un facteur indispensable à la bonne conservation du lait bouilli.

\section{CONCLUSION}

Dans l'état sanitaire actuel du cheptel français $(8,5 \%$ de bovins tuberculeux) [19], l'ébullition domestique du lait est une mesure d'hygiène indispensable pour toutes les personnes qui ne 
disposent que de lait cru. De plus elle est une mesure de sagesse pour celles qui utilisent le lait pasteurisé livré en bidons, très souvent recontaminé au cours des manipulations de distribution. Enfin l'ébullition est encore nécessaire pour le lait destiné à l'alimentation des nourrissons, car la flore même banale de ce lait doit être réduite au minimum au moment où le lait est absorbé par l'enfant. Dans tous ces cas, le lait sera conservé au froid après I'achat et porté à l'ébullition immédiatement avant l'emploi ou encore, mais ce procédé est moins économique, le lait sera refroidi aussitôt après l'ébullition puis conservé au frais ( $15^{\circ}$ maximum) et consommé dans les vingt-quatre heures. Nous rejoignons ici les conclusions de J. Renault et P.-P. Lévy [4] que nous avons citées au début de cet exposé.

A côté de l'intérêt indiscutable qu'il présente dans les conditions qui viennent d'être énumérées, le procédé de l'ébullition domestique comporte certains inconvénients inhérents au procédé lui-même ou aux conditions pratiques dans lesquelles il est appliqué. En France, par exemple, l'ébullition du lait au domicile du consommateur est une habitude presque générale. Mais quels que soient l'origine du lait et les traitements qu'il a subis avant la vente, quelle qu'en soit la destination (consommation à l'état liquide ou utilisation dans la cuisine), aucune règle précise n'est appliquée pour cette ébullition, en particulier le refroidissement du lait après l'ébullition est loin d'être une pratique courante.

L'ébullition domestique est un procédé onéreux par les pertes de substances nutritives qu'il entraîne, les dépenses d'énergie calorifique qu'il nécessite et enfin le travail qu'il impose à la ménagère. Dans le cas de la consommation urbaine l'ébullition succède presque toujours à une pasteurisation, indispensable pour la conservation du lait pendant son transport et sa distribution. Cette ébullition du lait pasteurisé accrô̂t encore notablement le prix de revient du lait à la consommation.

L'ébullition n'apporte pas toujours une garantie d'hygiène totale, en effet, les spores de germes aérobies ou anaérobies susceptibles de se développer rapidement après l'ébullition sont présentes dans tous les laits que nous avons examinés. Les laits contenant ces spores, soumis à l'ébullition et conservés à $24^{\circ}$, ne sont en général pas visiblement altérés après vingt-quatre heures, mais ils contiennent déjà une nombreuse population microbienne : cette population est, le plus souvent, de plusieurs millions de germes par centimètre cube. Elle est parfois constituée de germes capables de provoquer des toxi-infections alimentaires : le lait a déjà subi à ce moment un début de putréfaction. 
Au point de vue de la destruction des microbes pathogènes, l'ébullition n'est pas supérieure à une pasteurisation bien faite.

Au point de vue de la durée de conservation du lait, elle n'offre pas non plus d'avantages définis sur le procédé de pasteurisation correctement appliqué, e'est-à-dire comportant une répartition à l'abri de toute contamination et une distribution en récipients fermés.

Nous exprimons notre reconnaissance à M. Mocquot qui, par ses conseils, nous a guidé tout au cours de ce travail.

\section{'RÉFÉRENCES BIBLIOGRAPHIQUES}

[1] G. S. Wilson. The pasteurisation of milk. Arnold, Londres, 1948.

[2] E. Duclaux. Principes de laiterie. Armand Colin, Paris, 1890.

[3] L. Pasteur. Euvres. Masson, Paris, 1922, 2, 194, 254, 262.

[4] J. Renault et P. P. Lévy. Revue d'hygiène et de police sanitaire, 38, $737,1916$.

[5] H. D. KAX et coll. La pasteurisation du lait. Organisation mondiale de la santé, Genève, 1954.

[6] J. D. Ridgway. Some recent observations on the bacteriology of sterilized milk. Journal Appl. Bact., 18, 374-387, 1955.

[7] N. R. Smith, R. E. Gordon et F. E. Clark. Aerobic mesophilic sporeforming bacteria. Misc. Publ. U.S. Dep. Agric., 559, 1956.

[8] B. C. J. G. Kniaht et H. Proom. A comparative survey of the nutrition and physiology of mesophilic species in the genus Bacillus. Journal Gen. Mierab., 4, 508-538, 1950.

[9] B. Paquet et D. Gauvin. Fréquence et signification des clostridium à fermentation gazeuse dans le lait. Canad. Journal publ. Health, 44, $22,1953$.

[10] R. Buttiaux et H. Beerens. Les indices de propreté originelle des laits pasteurisés. Rev. path. gen. comp., 53, 1448-1452, 1953.

[11] E. Grinsted et L. F. L. ClegG. Spore forming organisms in commercial sterilized milk. Journal Dairy Res., 22, 178-190, 1955.

[12] S. J. ROWLAND. The determination of the nitrogen distribution in milk. Journal Dairy Res., 9, 43-46, 1938.

[13] A. R. Prévot et H. Thouvenot. Le lait peut-il transmettre les maladies à anaérobies? Ann. Inst. Pas., 83, 180-185, 1952.

[14] B. C. Hobbs, M. E. Smith, C. L. OAkley, G. H. Warrack et J. C. CrUICKSHANK. Clostridium welchii food poisoning. Journal Hyg., 51, 75-101, 1953.

[15] L. S. McClung. Human food poisoning due to the growth of Clostridium perfringens in freshly cooked chicken. Journal Bact., 50, 229-234, 1945.

[16] R. Meyer. Ueber zwei Nahrungsmittelvergiftungen durch Keime der Mesentericus-Subtilis-Gruppe. Zeitschr. Hyg. Infekt Krankh, 133, $211 \cdot 216,1951$. 
[17] J. E. Auclair et A. Portmans. Influence du chauffage du lait sur le développement des bactéries. Ann. Inst. Nat. Rech. agron., Série E (Ann. techn. agric.), 4, 121-131, 1955.

[18] A. Hrrsch et E. Grinsted. Methods for the growth and enumeration of anaerobic spore formers from cheese with observation on the effect of nisin. Journal Dairy Res., 21, 101-109, 1954.

[19] R. Vuillaume. Organisation actuelle de la lutte contre la tuberculose bovine. Bull. Acad. Vet., 28, 283-298, 1955.

[20] G. Mocquot. Aspects techniques et hygiéniques du problème des laits destinés à la consommation. Ann. Nutr., 9, 251'-270, 1955.

[21] Th. E. Galeslopt. Some aspects of the bacteriology of pasteurised milk. and Dairy J., 7, 1-14, 1953.

\title{
ÉVOLUTION DE LA VALEUR VITAMINIQUE DU GRUYERE AUX DIVERS STADES DE SA FABRICATION (1)

\author{
par
}

\author{
Mme L. RANDOIN et M. J. CAUSERET
}

(Note présentée par M. Mocquot, Correspondant)

La transformation du lait en fromages s'accompagne de modifications importantes de sa valeur vitaminique initiale.

Une partie des vitamines est perdue par divers processus : passage dans le lactosérum au cours de l'égouttage du caillé, destruction au cours de la maturation, etc.. Mais simultanément, la microflore qui se développe à la surface des fromages (ou en profondeur dans le cas de quelques espèces), réalise la synthèse de facteurs du groupe B, qui s'accumulent localement ou diffusent en proportions plus ou moins élevées dans les autres parties des fromages. En général, les pertes sont supérieures aux quantités synthétisées.

Malheureusement, les recherches qui ont conduit à ces conclusions sont presque toutes partielles : seule, la comparaison de leurs résultats permet de reconstituer de manière approximative l'évolution de la valeur vitaminique des fromages.

Il nous a donc paru intéressant d'essayer de suivre cette évolution de manière systématique, en dosant les vitamines dans des caillés, puis dans les fromages obtenus à partir de ces caillés, à divers moments du séjour en cave. La présente note rend compte des résultats de l'étude réalisée, suivant ce plan, sur le Gruyère de

(1) Compte Rendu Acad. Agric., 1956, 42, no 15, 727. 